\title{
Lumbar Disc Disease
}

\section{August 2002}

David G. Malone, M.D.

Oklahoma Spine and Brain Institute, Tulsa, Oklahoma

Neurosurgeons should strive to undertake treatment of their patients and to make more accurate diagnoses of their diseases. The spectrum of lumbar disc disease ranges from disc herniation with radiculopathy to simple degeneration of the disc causing intermittent low-back pain.

In this issue of Neurosurgical Focus we examine the anatomical and pathophysiological features of the lumbar disc; consider controversial topics such as discography, annuloplasty, and nucleoplasty; learn newer techniques of lumbar discectomy; benefit from expert how-to reports; look at a literature-based guideline on the use of discography; see how outcomes research can be applied to diseases of the lumbar spine; and receive an update on artificial disc technology.

It is hoped that this issue will inspire further thought about lumbar disc disease so that we can diagnose earlier, intervene less invasively, and create better long-term outcomes for our patients. 